\title{
PRE-TRAINING HYDRATION STATUS OF WELL- TRAINED SOCCER PLAYERS IN MODERATE TEMPERATURE AUTUMN AND COOL WINTER
}

\author{
Lilita Voitkevica ${ }^{1}$, Inese Pontaga ${ }^{1}$, Saima Timpmann²,3, Vahur Ööpik ${ }^{2,3}$ \\ Latvian Academy of Sport Education ${ }^{1}$, Riga, Latvia \\ Institute of Exercise Biology and Physiotherapy, University of Tartu', Tartu, Estonia \\ Estonian Centre of Behavioural and Health Sciences, University of Tartu ${ }^{3}$, Tartu, Estonia
}

\begin{abstract}
Background. Pre-training hydration status is considered a factor influencing efficacy of training. Research literature does not contain data regarding the potential impact of natural alternation of seasons on pre-training hydration status in athletes. The purpose of this study was to assess and compare pre-training hydration status in well-trained male soccer (football) players in moderate temperate autumn and cold winter.

Methods. Research participants were 57 male soccer players from two Latvian First League teams, who were studied prior to their ordinary training session. Participants provided a midstream urine sample for analysis of urine specific gravity (USG), and their body mass ( $\mathrm{kg}$ ), body fat percentage and total body water percentage were measured.

Results. Pre-training hydration status did not differ in moderate temperature autumn (mean USG $1.020 \pm 0.010$; mean total body water $64.2 \pm 2.9 \%$ ) in cold winter (mean USG $1.020 \pm 0.008$; mean total body water $64.8 \pm 2.7 \%$; for both parameters $p>.05$ ). Prevalence of hypohydration and serious hypohydration (defined as USG $1.021-1.030$ and USG $>1.030$, respectively) was similar in moderate temperate autumn $(47.4 \%)$ and cold winter $(60 \%),\left(\chi^{2}=\right.$ $1.50 ; p>.05)$. Significant correlation between the within-subject USG values measured in moderate temperate and cold environment was observed $(r=.60, p=.009)$.

Conclusion. In well-trained soccer players pre-training hydration status does not differ in moderate temperature autumn and cold winter. Individual-related factors such as nutritional behaviour (including pattern of voluntary fluid intake) may have stronger impact on hydration status than environment-related factors like natural alternation of seasons.
\end{abstract}

Keywords: hydration status, football, environmental temperature, autumn, winter.

\section{INTRODUCTION}

$\mathrm{S}$ occer (football) could be considered an endurance sport involving $90 \mathrm{~min}$ of varying-intensity exercise (Reilly, Bangsbo, \& Franks, 2000) and placing high demand on cognitive abilities of athletes (Burke \& Hawley, 1997). Due to prolonged nature and depending on environmental conditions, a competitive soccer match may induce sweat losses in the range of approximately 0.8 to $2.6 \mathrm{~L}$ (Burke \& Hawley, 1997). However, in some individuals in hot humid weather sweat losses up to $3.5 \mathrm{~L}$ (Ekblom, 1986) or even 3.9 L (Burke \& Hawley, 1997) have been observed.
Regarding training sessions, Maughan, Shirreffs, Merson and Horswill (2005) reported mean sweat losses from 1.7 L in cool humid environment (air temperature $5^{\circ} \mathrm{C}$, relative humidity $81 \%$ ) to $2.2 \mathrm{~L}$ in hot humid weather (air temperature $28^{\circ} \mathrm{C}$, relative humidity $56 \%$ ).

It is a common finding that soccer players do not fully replace sweat losses by fluid intake during a competitive match or a training session, neither in cool nor in hot environment (Burke \& Hawley, 1997; Kurdak et al., 2010; Maughan et al., 2005). According to Burke and Hawley (1997), 
fluid replacement lags behind water losses through sweating by approximately $50 \%$ independently of weather conditions. Therefore, dehydration occurs during competitive matches and training sessions, usually in the range of $1-3 \%$ of body mass (Burke \& Hawley, 1997; Kurdak et al., 2010; Maughan et al., 2005). Shirreffs (2010) recently summed up that the average calculated sweat losses, fluid intake and degree of dehydration for soccer players is typically in the order of $1.5 \mathrm{~L} / \mathrm{h}, 0.7 \mathrm{~L} / \mathrm{h}$ and $1.5 \%$, respectively.

There is evidence that even mild dehydration may impair physical performance in soccer players. Guerra, Chaves, Barros and Tirapegui (2004) studied young male athletes participating in a 75-min football game in a hot environment under two conditions: with and without ingestion of a $6 \%$ carbohydrate-electrolyte drink. Mean body mass loss of 1.14 and $1.75 \mathrm{~kg}$ during the games with and without drink ingestion revealed approximately 1.7 and $2.6 \%$ dehydration, respectively. Approximately $0.9 \%$ greater dehydration without fluid ingestion associated with significantly reduced time spent running and the number of sprints performed in comparison with the game with fluid ingestion. Similarly, Edwards et al. (2007) reported that moderate dehydration (approximately $2.4 \%$ of body mass) was detrimental to performance in a soccerspecific test. Shirreffs (2010) has generalized that soccer players, in order to avoid decrease in physical performance, should limit the degree of dehydration to less than $2 \%$ of body mass loss.

The impact of dehydration on cognitive function is less clear. In young adults there is little evidence that dehydration disrupts cognition, but both elderly adults and children may be at higher risk (Benton, 2011). Regarding soccer players, Bandelow et al. (2010) reported that in young males exercising in the heat dehydration up to $2.5 \%$ of body mass had no clear effect on cognitive function, and Edwards et al. (2007) observed a decrease in physical performance but no impairment of mental concentration in moderately dehydrated young males.

It is important to recognize, that keeping the degree of dehydration within the acceptable limit of approximately $2 \%$ during a match or training session may be not possible if the players begin exercise in a hypohydrated state. Hence, pretraining hydration status in soccer players should be considered an important factor potentially influencing efficacy of training. Surprisingly, data regarding pre-training hydration status in soccer players is scarce. Maughan et al. (2005) studied elite male soccer players training in a cool environment $\left(5^{\circ} \mathrm{C}\right)$ and reported pre-training mild hypohydration (defined as urine osmolality above $900 \mathrm{mOsm} / \mathrm{kg}$ ) in $35 \%$ of athletes. Da Silva et al. (2012) monitored elite male Brazilian adolescent soccer players during three consecutive training days in the heat $\left(27.6-33.1^{\circ} \mathrm{C}\right)$ and observed occurrence of pre-practice hypohydration in 45 $85 \%$ of athletes in different days. Regarding other team sports, Stover, Zachwieja, Stofan, Murry and Horswill (2006 a) observed consistently high pretraining urine specific gravity (USG) indicating hypohydration in a group of adolescent American football players during five consecutive days of twoa-day practices in mild environmental conditions (wet bulb globe temperature $15.5-23.2^{\circ} \mathrm{C}$ ). Furthermore, although it is commonly recognized that environmental temperature influences body water balance (Sawka et al., 2007), there seems to be no studies providing direct comparison of pre-practice hydration status in soccer players training in different environmental conditions due to natural alternation of seasons.

Thus, considering the paucity of relevant data in the literature, the purpose of this study was to assess and compare pre-training hydration status in well-trained male soccer players in autumn and in winter, i.e. in moderate temperate and cold environmental conditions.

\section{METHODS}

Participants. Fifty-seven male soccer players from two teams of the First League of the Latvian Football Federation voluntary participated in the study the protocol of which was approved by the Ethics Committee of Latvian Academy of Sports Education. At the beginning of the study, the mean age of the participants was $21.5 \pm 3.2$ years. They had nine to ten years training experience in soccer and they had regular training sessions or competitive matches of 1.5-2 hour duration six times per week on average.

Study design. We compared pre-training hydration status and body composition in well trained male soccer players in moderate temperate and cold environments. Therefore we asked the participants to consume the fluid as they usually did according to their subjective thirst sensation and not to change their drinking habits before training. The pre-training urine samples of soccer players were collected within two days at the end of August and at the beginning of September (in autumn). The average ambient temperature at that time was $16^{\circ} \mathrm{C}$ 
and $13^{\circ} \mathrm{C}$ for August and September, respectively. Forty soccer players from the same two teams participated in the study again in cold environment in February and the first week of March (in winter). The average ambient temperature in that period was between $-1.9^{\circ} \mathrm{C}$ and $-5^{\circ} \mathrm{C}$.

Anthropometry and body composition analysis. Athlete's height was measured by Ultrasound Height Measuring Unit MZ10020 (ADE, Hamburg). Body mass (to the nearest $0.1 \mathrm{~kg}$; wearing briefs), body fat percentage and total body water content in percent were measured using Body Composition Analyzer BC-418 manufactured by Tanita Corporation, Japan.

Urine sampling, analysis and interpretation of the USG values. Before training, participants provided a midstream urine sample into a sterile polyurethane container $(15 \mathrm{ml}$, Sarsted Aktiengesellschaft \& Co, Germany). USG was measured within three hours after collection of the samples using digital hand held refractometer PAL-10S (Atago, USA). USG measuring range of this device is $1.000-1.060$, resolution 0.001 and accuracy \pm 0.001 units.

Some discrepancy exists in the literature regarding the definitions of euhydration and hypohydration based on USG values. In particular, USG values of 1.010-1.020, which are considered consistent with euhydration according to American College of Sports Medicine (Sawka et al., 2007) and National Collegiate Athletic Association (National Collegiate Athletic Association, 2003) criteria, indicate minimal hypohydration compared to the National Athletic Trainers' Association's (NATA) more detailed classification system (Casa et al., 2000). In the current paper, we classify our soccer players with USG $\leq 1.020$ "euhydrated", those with
USG 1.021-1.030 "hypohydrated", and those with USG > 1.030 "seriously hypohydrated".

Statistics. The SPSS version 20 software was used for the statistical analysis of the data. The mean values and standard deviations were calculated for all characteristics. An independent $t$-test was employed to determine differences between the characteristics in the temperate and cold environment. $\chi^{2}$ analysis was performed to compare the prevalence of hypohydration status among the soccer players in moderate temperate and cold environments, and linear correlation analysis was used to determine relationships between various characteristics. Statistical significance was set at $p<.05$.

\section{RESULTS}

The anthropometric and body composition data of the participants are summarized in Table.

In temperate environmental conditions, euhydrated status (USG $\leq 1.020)$ was observed in 30 soccer players out of 57 , i. e. in $52.6 \%$ of the athletes participating in the study (Figure 1). Hypohydration (USG 1.021-1.030) was evident in 25 athletes $(43.9 \%)$, and serious hypohydration (USG $>1.030$ ) occurred in 2 athletes $(3.5 \%)$.

In cold environment, 16 soccer players out of $40(40 \%)$ were euhydrated (Figure 2), 23 athletes (57.5\%) were hypohydrated, and 1 athlete $(2.5 \%)$ was seriously hypohydrated.

$\chi^{2}$ analysis revealed that the prevalence of hypohydration and serious hypohydration among soccer players studied did not differ in moderate temperate $(47.4 \%)$ and cold $(60 \%)$ environment $\left(\chi^{2}\right.$ $=1.50 ; p>.05)$.

In those 40 soccer players who participated in the study both in autumn and winter, a positive

\begin{tabular}{|l|c|c|c|}
\hline \multicolumn{1}{|c|}{ Environment conditions } & $\begin{array}{c}\text { Moderate temperate } \\
\text { environment } \\
\left(\mathbf{1 3}^{\circ} \mathbf{C}-\mathbf{1 6}^{\circ} \mathbf{C}\right)\end{array}$ & $\begin{array}{c}\text { Cold environment } \\
\left(-\mathbf{1 . 9}^{\circ} \mathbf{C}-\mathbf{5}^{\circ} \mathbf{C}\right)\end{array}$ & $\begin{array}{c}\text { Statistical } \\
\text { significance of } \\
\text { difference }\end{array}$ \\
\hline Number of players & 57 & 40 & - \\
\hline Age (years) & $22.0 \pm 2.8$ & $20.6 \pm 3.6$ & not significant \\
\hline Height $(\mathrm{cm})$ & $182 \pm 6$ & $180 \pm 7$ & not significant \\
\hline Body mass $(\mathrm{kg})$ & $76.7 \pm 8.0$ & $76.7 \pm 8.3$ & not significant \\
\hline Body mass index $\left(\mathrm{kg} / \mathrm{m}^{2}\right)$ & $23.2 \pm 1.7$ & $23.6 \pm 2$ & not significant \\
\hline Body fat $(\%)$ & $10.8 \pm 3.6$ & $10.5 \pm 3.2$ & not significant \\
\hline Body water $(\%)$ & $64.2 \pm 2.9$ & $64.8 \pm 2.7$ & not significant \\
\hline USG & $1.020 \pm 0.010$ & $1.020 \pm 0.008$ & not significant \\
\hline USG range & $1.004-1.034$ & $1.004-1.031$ & - \\
\hline
\end{tabular}

Table 1. The anthropometric and body composition data and pre-training urine specific gravity (USG) of well-trained soccer players in moderate temperate and cold environments 


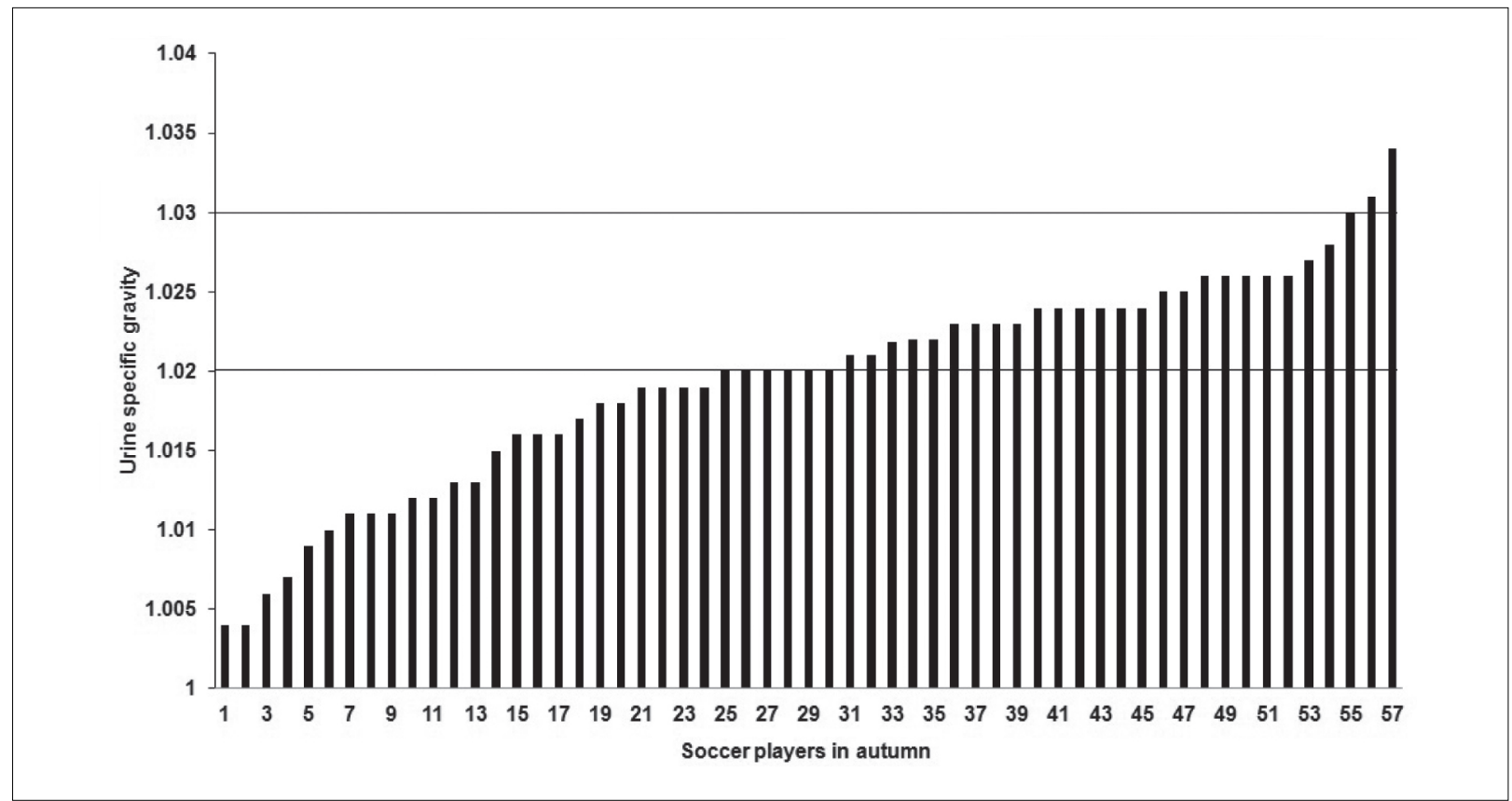

Figure 1. Individual values of pre-training urine specific gravity in soccer players in moderate temperate environment (in autumn). Horizontal lines at $\mathbf{1 . 0 2}$ and $\mathbf{1 . 0 3}$ indicate cut-off values for hypohydration and serious hypohydration, respectively

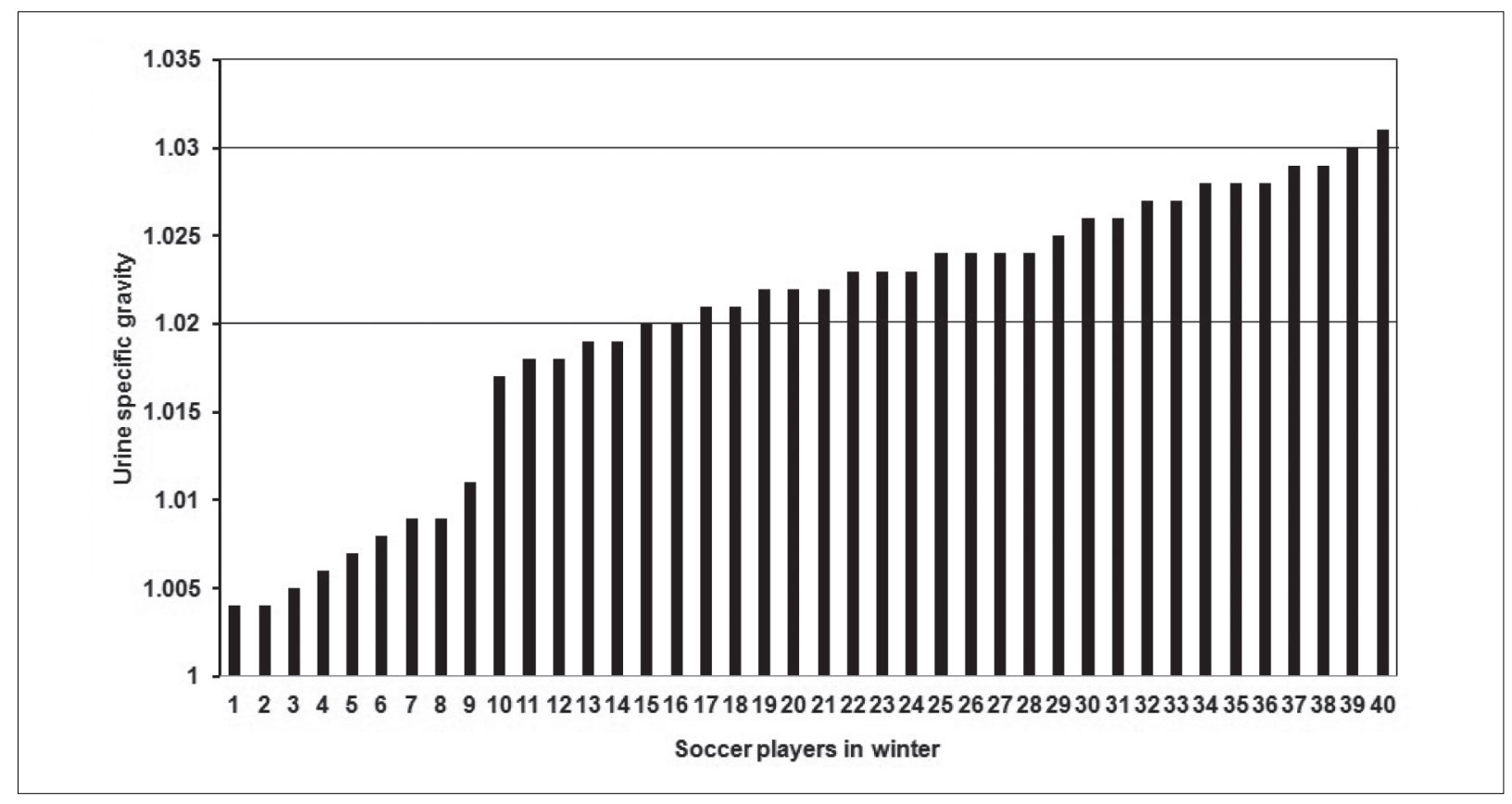

Figure 2. Individual values of pre-training urine specific gravity in soccer players in cold environment (in winter). Horizontal lines at 1.02 and $\mathbf{1 . 0 3}$ indicate cut-off values for hypohydration and serious hypohydration, respectively

significant correlation between the USG values measured in moderate temperate and cold environment was observed $(r=.60, p=.009)$. This relationship is characterized by the equation: USG (winter) $=0.572+0.440 \cdot$ USG (autumn), the standard error of the equation is 0.005 .
The correlation between the body fat percentage and pre-training urine specific gravity was not significant $(r=.02, p=.87)$. Similarly, the correlation between the total body water percentage and pre-training urine specific gravity was not significant $(r=.002, p=.99)$. 


\section{DISCUSSION}

The novelty of this study was repeated assessment of pre-training hydration status in a group of well-trained soccer players in the environmental conditions that changed due to the natural alternation of seasons. Such approach enabled to elucidate the potential influence of a season on hydration status in athletic community. The main finding of the study was that pre-training hydration status evaluated on the basis of USG and body water percentage did not differ in moderate temperature autumn and cold winter in the athletes studied. In the two environmental conditions mean pre-training USG was identical (1.020) and body water percentage (mean values 64.2 and 64.8 in autumn and in winter, respectively) was similar.

An accurate assessment of the hydration status of the human body is a difficult task and there is no single gold standard method for that (Armstrong, 2007). Nevertheless, USG is considered an acceptably valid indicator of hydration status (Armstrong et al., 2010; Bartok, Schoeller, Sullivan, Clark, \& Landry, 2004; National Collegiate Athletic Association, 2003; Oppliger \& Bartok, 2002; Sawka et al., 2007) and it is commonly used in the field of sports medicine and exercise science for both practical and scientific purposes (Da Silva et al., 2012; Osterberg, Horswill, \& Baker, 2009; Stover et al., 2006 a, b; Volpe, Poule, \& Bland, 2009). Generally, USG of $\leq 1.020$ is considered consistent with euhydration whereas USG > 1.020 refers to hypohydration (National Collegiate Athletic Association, 2003; Oppliger \& Bartok, 2002; Popowski et al., 2001; Sawka et al., 2007). NATA's more detailed classification system differentiates a well-hydrated status (USG values $<$ 1.010), minimal (USG values 1.010-1.020), significant (USG values 1.021-1.030) and serious (USG values $>1.030$ ) hypohydration (Casa et al., 2000). In the current study, we applied a combined approach and classified our soccer players with USG $\leq 1.020$ as euhydrated, those with USG $1.021-1.030$ as hypohydrated, and those with USG $>1.030$ as seriously hypohydrated.

Although the average pre-training USG value of 1.020 observed in our players was consistent with the upper range of euhydration, the prevalence of hypohydration and serious hypohydration was notably high in both temperate and cold environments (47.4 and 60\%, respectively). Significant positive correlation between USG values measured in autumn and winter suggest that individual-related factors such as nutritional behaviour may have stronger impact on hydration status than environment-related factors like natural alternation of seasons. Generally, our findings are consistent with the observation of Stover et al. (2006 b) who reported similar average pre-training USG values in two big groups of recreational exercisers living in Chicago and Los Angeles, where the ambient temperature during the study averaged $-5^{\circ} \mathrm{C}$ and $20.6^{\circ} \mathrm{C}$, respectively. These authors (Stover et al., 2006 b) did not report the prevalence of pre-training hypohydration for the two groups separately, but in the pooled sample from the two cities the prevalence was $49 \%$. Altogether the data of the two studies (Stover et al., $2006 \mathrm{~b}$; the current one) suggest that in the range of ambient temperature from $-5^{\circ} \mathrm{C}$ to $21^{\circ} \mathrm{C}$ maintenance of body fluid balance presents about equal challenge in the athletic community.

$\chi^{2}$ analysis revealed similar prevalence of hypohydration and serious hypohydration in our soccer players in moderate temperate autumn and cool winter, but it still deserves attention that the relevant numerical value was greater in the cool season. Difficulties in maintaining body fluid balance in cool climate could be explained by the changed thirst sensation. Kenefick, Hazzaed, Mahood, and Castellani (2004) demonstrated that when either euhydrated or hypohydrated, thirst at rest and during moderate-intensity exercise was attenuated by up to $40 \%$ in cool compared to moderate temperate environment in young men. Maughan et al. (2005) compared sweat losses and fluid intake in football players training in temperate $\left(25^{\circ} \mathrm{C}\right.$, relative humidity $\left.60 \%\right)$ and cool $\left(5^{\circ} \mathrm{C}\right.$, relative humidity $\left.81 \%\right)$ environments. Sweat losses were only $8.1 \%$ greater in moderate temperate environment, but fluid intake exceeded that observed in cool conditions by $97.2 \%$. As a result of a substantial difference in voluntary fluid consumption, acute training-induced dehydration was greater $(1.62 \%$ of body mass) in cool than in moderate temperate environment (1.22\%).

According to Casa et al. (2000), USG values between 1.021 and 1.030 may correspond to a degree of hypohydration of 3-5\% of body mass, and Shirreffs (2010) suggested that soccer players, in order to avoid decrease in physical performance, should limit the degree of dehydration to less than $2 \%$ of body mass. If these estimates are correct, then it is likely that in our soccer players who were hypohydrated prior to training, performance was suboptimal during the whole subsequent training 
session. The likelihood of negative impact of pretraining hypohydration on performance is further supported by the data of previous research which exclusively showed that soccer players were not able to compensate sweat losses with fluid consumption during training in warm (Da Silva et al., 2012; Duffield, McCall, Coutts, \& Peiffer, 2012) and in cool (Maughan et al., 2005) environment. Therefore, in players who are hypohydrated before training the degree of dehydration developing during training is certainly greater than in players who start training in euhydrated status. Consequently, in players experiencing hypohydration before training, relatively greater decrease in performance during training could be expected. In a long-time perspective, such a scenario could lead to suboptimal efficacy of the whole training process.

It is important to note that the scenario outlined in the preceding paragraph is logical, but still speculative. To the best of our knowledge, no study has directly evaluated the relationship between pretraining USG and performance during subsequent training session in well-trained soccer players. Nevertheless, literature suggests that pre-practice hypohydration of a similar degree as observed in our soccer players may indeed significantly impair performance. Recently Davis et al. (2014) studied well-trained recreational runners who completed a $10-\mathrm{km}$ run in two cases: being euhydrated (prerun mean USG in the group 1.014) or hypohydrated (pre-run mean USG 1.026). In these runners, prerun hypohydration associated with a significant $3 \%$ decrease in performance compared to pre-run euhydrated status. High-standard soccer players cover similar distance $(9.7-11.0 \mathrm{~km})$ during a competitive game (Mohr, Krustrup, \& Bangsbo, 2003) and their training bouts are of the same magnitude. Therefore, further studies with the aim to assess potential relationship between pre-training USG and subsequent soccer-specific performance in well-trained players seem to be warranted.
Hypohydration can compromise cardiovascular function, heat dissipation and exercise performance (Maughan, 2003). Chronic hypohydration and inadequate fluid consumption have been linked to chronic illnesses (Stookey, Purser, Pieper, \& Cohen, 2004). Therefore, our findings suggest that evidence-based recommendations and qualified guidance for adequate fluid replacement are needed for high level soccer players.

\section{CONCLUSIONS}

The results of this study indicate that in welltrained soccer players pre-training hydration status evaluated on the basis of USG and body water percentage does not differ in moderate temperature autumn and cold winter. The results also suggest that individual-related factors such as nutritional behaviour (including pattern of voluntary fluid intake) may have stronger impact on hydration status than environment-related factors like natural alternation of seasons. High prevalence (47-60\%) of pre-training hypohydration warrants further research to elucidate potential relationship between pre-training USG and subsequent soccer-specific performance in well-trained players and refers to the need for evidence-based recommendations and qualified guidance for adequate fluid replacement for high level soccer players.

\section{ACKNOWLEDGEMENTS}

This research has been supported by the European Social Fund within the project "Support for Sport Science" No. 2009/0155/1DP/1.1.2.1.2/09/ IPIA/VIAA/010 action programme „Human resources and Employment" 1.1.2.1.2. subactivity "Support for Doctoral Study Programme Implementation", and by institutional research funding IUT 20-58 of the Estonian Ministry of Education and Research.

\section{REFERENCES}

Armstrong, L. (2007). Assessing hydration status: The elusive gold standard. Journal of the American College of Nutrition, 26(5), 575S-584S.

Armstrong, L. E., Pumerantz, A. C., Fiala, K. A., Roti, M. W., Kavouras, S. A., Casa, D. J., \& Maresh, C. M. (2010). Human hydration indices: Acute and longitudinal reference values. International Journal of Sport Nutrition and Exercise Metabolism, 20(2), 145-153.

Bandelow, S., Maughan, R., Shirreffs, S. M., Ozgünen, K. T., Kurdak, S., Ersöz, G., ... Dvorak, J. (2010). The effects of exercise, heat, cooling and rehydration strategies on cognitive function in football players. Scandinavian Journal of Medicine and Science in Sports, 20(3), 90-94. 
Bartok, C., Schoeller, D. A., Sullivan, J. C., Clark, R. R., \& Landry, G. L. (2004). Hydration testing in collegiate wrestlers undergoing hypertonic dehydration. Medicine and Science in Sports and Exercise. 36(3), 510-517.

Benton, D. (2011). Dehydration influences mood and cognition: A plausible hypothesis? Nutrients, 3(5), 555-573. doi:10.3390/nu3050555

Burke, L. M., \& Hawley, J. (1997). Fluid balance in team sports - guidelines for optimal practices. Sports Medicine, 24(1), 38-54.

Casa, D. J., Armstrong, L. E., Hillman, S. K., Montain, S. J., Reiff, R. V., Rich, B. S. E., ... Stone, J. A. (2000). National Athletic Trainers' Association position statement: fluid replacement for athletes. Journal of Athletic Training, 35(2), 212-224.

Da Silva, R. P., Mündel, T., Natali, A. J., Bara Filho, M. G., Alfenas, R. C. G., Lima, J. R. P., ... Marins, J. C. B. (2012). Pre-game hydration status, sweat loss, and fluid intake in elite Brazilian young male soccer players during competition. Journal of Sports Sciences, 30(1), 37-42. doi:10.1080/02640414.2011.6 23711

Davis, B. A., Thipgen, L. K., Hornsby, J. H., Green, J. M., Coates, T. E., \& O’Neal, E. K. (2014). Hydration kinetics and $10-\mathrm{km}$ outdoor running performance following $75 \%$ versus $150 \%$ between bout fluid replacement. European Journal of Sport Science, 14(7), 703-710.

Duffield, R., McCall, A., Coutts, A. J., \& Peiffer, J. J. (2012). Hydration, sweat and thermoregulatory responses to professional football training in the heat. Journal of Sports Science, 30(10), 957-965.

Edwards, A. M., Mann, M. E., Marfell-Jones, M. J., Rankin, D. M., Noakes, T. D., \& Shillington, D. P. (2007). Influence of moderate dehydration on soccer performance: Physiological responses to $45 \mathrm{~min}$ of outdoor match-play and the immediate subsequent performance of sportspecific and mental concentration tests. British Journal of Sports Medicine, 41(6), 385-391.

Ekblom, B. (1986). Applied physiology of soccer. Sports Medicine, 3, 50-60.

Guerra, I., Chaves, R., Barros, T., \& Tirapegui, J. (2004). The influence of fluid ingestion on performance of soccer players during a match. Journal of Sports Science and Medicine, 3(4), 198-202.

Kenefick, R. W., Hazzard, M. P., Mahood, N. V., \& Castellani, J. W. (2004). Thirst sensations and AVP responses at rest and during exercise-cold exposure. Medicine and Science in Sports and Exercise, 36(9), 1528-1534. doi: 10.1249/01. MSS.0000139901.63911.75

Kurdak, S. S., Shirreffs, S. M., Maughan, R. J., Ozgunen, K. T., Zeren, C., Korkmaz, S. et al. (2010). Hydration and sweating responses to hot-weather football competition. Scandinavian Journal of Medicine and Science in Sports, 20 (Suppl. 3), 133-139. doi: 10.1111/j.1600-0838.2010.01218.x.

Maughan, R. J. (2003). Impact of mild dehydration on wellness and on exercise performance. European Journal of Clinical Nutrition, 57(2), S19-S23. doi:10.1038/ sj.ejcn.1601897

Maughan, R. J., Shirreffs, S. M., Merson, S. J., \& Horswill, C. A. (2005). Fluid and electrolyte balance in elite male football (soccer) players training in a cool environment. Journal of Sports Sciences, 23(1), 73-79. doi: 10.1080/02640410410001730115

Mohr, M., Krustrup, P., \& Bangsbo, J. (2003). Match performance of high-standard soccer players with special reference to development of fatigue. Journal of Sports Sciences, 21(7), 519-528.

National Collegiate Athletic Association. (2003). NCAA Wrestling Rules and Interpretations. Indianapolis: National Collegiate Athletic Association.

Oppliger, R. A., \& Bartok, C. (2002). Hydration testing of athletes. Sports Medicine, 32(15), 959-971.

Osterberg, K. L., Horswill, C. A., \& Baker, L. B. (2009). Pregame urine specific gravity and fluid intake by national basketball association players during competition. Journal of Athletic Training, 44(1), 53-57.

Reilly, T., Bangsbo, J., \& Franks, A. (2000). Anthropometric and physiological predispositions for elite soccer. Journal of Sports Sciences, 18(9), 669-683.

Sawka, M. N., Burke, L. M., Eichner, E. R., Maughan, R. J., Montain, S. J., \& Stachenfeld, N. S. (2007). American College of Sports Medicine position stand. Exercise and fluid replacement. Medicine and Science in Sports and Exercise, 39(2), 377-390.

Shirreffs, S. (2010). Hydration: Special issue for playing football in warm and hot environments. Scandinavian Journal of Medicine and Science in Sports, 20(3), 90-94.

Stookey, J. D., Purser, J. A., Pieper, C. F., \& Cohen, H. J. (2004). Plasma hypertonicity: Another marker of frailty? Journal of the American Geriatric Society, 52(8), 1313-1320. doi:10.1111/j.1532-5415.2004.52361.x

Stover, E. A., Petrie, H. J., Passe, D., Horswill, C. A., Murray, B., \& Wildman, R. (2006 b). Urine specific gravity in exercisers prior to physical training. Journal of Applied Physiology, Nutrition and Metabolism, 31, 320-327.

Stover, E. A., Zachwieja, J., Stofan, J., Murray, B., \& Horswill, C. A. (2006 a). Consistently high urine specific gravity in adolescent American football players and the impact of an acute drinking strategy. International Journal of Sports Medicine, 27, 330-335.

Volpe, S. L., Poule, K. A., \& Bland, E. G. (2009). Estimation of prepractice hydration status of National Collegiate Athletic Association Division I athletes. Journal of Athletic Training, 44(6), 624-629. 